\title{
Rede básica de serviços de saúde: médicos e suas representações sobre o serviço*
}

\author{
The basic health service network: doctors and their representations regarding \\ the service
}

\author{
Marcos de Souza Queiroz ${ }^{\star \star}$, Gastão Wagner de Souza Campos ${ }^{\star \star *}$, Emerson Elias Merhy
}

\begin{abstract}
QUEIROZ, M. de S. et al. Rede básica de serviços de saúde: médicos e suas representações sobre o serviço. Rev. Saúde públ., S. Paulo, 26: 34 - 40, 1992. Foram analisadas as representações de médicos do setor público de Campinas, tendo como referência o processo de municipalização dentro da reforma sanitária então em curso. Assume-se que o sucesso desta reforma dependerá amplamente da atitude que estes médicos terão em relação a seus vários aspectos. Os seguintes assuntos foram então focalizados para análise: as políticas e o gerenciamento dos serviços de saúde, o processo saúde-doença, o relacionamento médico-paciente e o trabalho em equipe envolvendo vários profissionais da saúde.
\end{abstract}

Descritores: Médicos. Antropologia. Sistemas locais de saúde.

\section{Introdução}

É argumento defendido no presente trabalho, em sintonia com o pensamento de Gramsci, que o nível das representações (entendido como uma dimensão da cultura) pode assumir importância decisiva na dinâmica social principalmente quando se trata de implementar políticas públicas. O modo como os médicos da rede básica de serviços de saúde percebem, avaliam e representam o processo de municipalização dos serviços é, assim, entendido como crucial para o sucesso do mesmo.

É oportuno lembrar, neste contexto, que a crise e a instabilidade própria do momento de transição por que passa o serviço público de saúde, o universo vivido e representado perde a segurança sustentada pela tradição para se colocar como objeto fragmentado, cujas partes se oferecem às várias tentativas de reconstrução tanto ao nivel concreto quanto simbólico. Tentativas nesse sentido adquirem um contorno mais definido numa dimensão política, uma vez que o universo institucional,

* Subvencionado pelo Ministério da Saúde e do Fundo de Apoio à Pesquisa da UNICAMP.

** Pesquisador do Núcleo de Estudos de Politicas Públicas da Universidade Estadual de Campinas - Campinas, SP . Brasil.

*** Departamento de Medicina Preventiva e Social da Faculdade de Ciências Médicas da Universidade Estadual de Campinas - Campinas, SP - Brasil.

Separatas/Reprints: M. de S. Queiroz - Caixa Postal 6166 Cidade Universitária Zeferino Vaz - 13081 - Campinas, SP Brasil.

Publicação financiada pela FAPESP. Processo Saúde Coletiva 91/4994-0 aberto às várias interpretações, e propostas de mudanças, torna-se inevitavelmente politizado.

Situações como esta são consideradas ideais para a análise antropológica, que concentra a sua investigação em contextos de pequena escala na tentativa de extrair bases consistentes para estabelecer conexões com dimensões sociais mais amplas. É também considerada ideal porque o mundo vivido nesta circunstância deixa de ser tomado unidimensionalmente como assentado em premissas e pressupostos solidos que, por isso mesmo, não se abrem para discussão e busca de coerência e sentido. Numa situação de transição, os valores perdem a sua condição de absolutos e a realidade passa a ser construída, interpretada, manipulada, destruída e reconstruída, tendo como matéria prima o confronto de valores múltiplos provenientes da situação vivida individual ou coletivamente pelos atores sociais. Deste modo, princípios culturais que normalmente não vêm à tona tornam-se explícitos e aparentes ao investigador. (Gluckman", 1966; Turner ${ }^{2}$, 1974).

Assim, pois, o presente trabalho objetiva analisar as representações de médicos do setor público, tendo como referência o processo de municipalização dentro da reforma sanitária então em curso.

\section{Metodologia}

Todos os cem médicos ativos da rede pública de saúde do Município de Campinas, Estado de São Paulo, responderam a um questionário, aplica- 
do na presença de um pesquisador ao longo do ano de 1988. Além dos autores, outros seis pesquisadores participaram do levantamento de dados a partir da aplicação do questionário. $O$ número relativamente grande de pesquisadores e a extensão de tempo relativamente ampla da pesquisa permitiram que o número de entrevistas coincidisse com o número de médicos da rede pública. $A$ análise estatística do questionário foi precedida de depuração dos dados por exame de consistência e de variação aceitável dos valores numéricos e categóricos.

- Todos os 36 coordenadores de Postos e Centros de Saúde, além de terem respondido ao questionário como os demais médicos, foram também entrevistados, dentro de um procedimento metodológico mais aberto e qualitativo.

\section{Perfil dos agentes de saúde da rede básica}

Na ocasião da presente pesquisa, trabalhavam nos Postos e Centros de Saúde de Campinas, um total de 235 servidores. Destes, 42,6\% são médicos e apenas $20,3 \%$ pertencem à área de enfermagem (enfermeiros, auxiliares de saúde e de enfermagem). Trata-se de uma proporção desequilibrada dado o modelo assistencial baseado principalmente no atendimento médico apoiado em serviços e procedimentos de enfermagem.

É freqüente a representação (anacrônica diante do desenvolvimento do sistema de saúde moderno) de que a rede básica de serviços de saúde teria uma composição de recursos humanos e de equipamentos bastante simplificada. No que se refere à área de recursos humanos, no entanto, os dados comprovam definitivamente que tal não ocorre, uma vez que $64,1 \%$ dos profissionais dessas unidades têm curso universitário completo. Por outro lado, a proporçāo $(9,8 \%)$ dos que têm formação técnica intermediária é insignificante, o que mostra uma distorção na composição do quadro de pessoal, visto que seria de se esperar para uma rede deste padrão uma percentagem bem maior de profissionais com nível técnico. Ao contrário do que se apregoa, é também pequena a parcela dos servidores com o curso primário incompleto $(9,0 \%)$.

A concentração de trabalhadores na faixa de 20 a 40 anos $(76,9 \%)$ corrobora a hipótese freqüentemente levantada de que, tanto para a carreira dos técnicos como para a dos profissionais com formação universitária, a rede básica constitui como que um primeiro degrau de suas vidas profissionais. Esta impressão é reforçada pelo fato de $80,0 \%$ dos profissionais universitários dessa rede terem menos de 10 anos de formatura, evidenciando uma tendência de mercado que leva principalmente os recém-formados a procurarem este tipo de emprego. Uma outra característica importante da totalidade dos agentes da rede pública de serviços de saúde de Campinas encontra-se no fato de que $75,6 \%$ deles serem do sexo feminino.

\section{Médicos}

Dos médicos da Rede Pública de Serviços de Saúde de Campinas, 74,3\% cumpriram programas completos de Residência Médica. Estes profissionais são contratados com a classificação de médicos de saúde pública, devendo teoricamente prestar assistência do tipo geral à clientela. No entanto, a percentagem de especialistas de fato é surpreendentemente alta, o que confirma a hipótese de que os serviços de assitência primária apresentam uma complexidade muito maior do que se poderia imaginar a partir da representação de "simplificação" tecnológica que o discruso desatento das grandes transformaçōes recentes verificadas no sistema de saúde ainda alimenta. Entre as principais áreas de especialização acadêmica, predomina a pediatria $(38,0 \%)$, seguida pela clínica $(20,0 \%)$, ginecologia $(15,0 \%)$, e medicina preventiva $(9,0 \%)$.

No que diz respeito à modalidade principal efetivamente exercida em mais de $50 \%$ da jornada de trabalho (incluindo também os períodos de trabalho realizados fora da rede pública) $35,0 \%$ apontaram a função de clínicos gerais ou internistas, $35,0 \%$ de pediatras, $14,0 \%$ de obstetras, $6,0 \%$ de sanitaristas e $10,0 \%$ de outras especialidades. Quanto à especialidade efetivamente realizada na rede básica, apenas $21,0 \%$ dos contratados desempenham a função de clínico geral, apesar de todos serem contratados com o objetivo de exercer este mesmo papel. Predominam os que exercem exclusivamente a Pediatria $(36,0 \%)$, o atendimento de adultos $(18,0 \%)$ e da mulher $(12,0 \%)$. É curioso que apenas $34,0 \%$ desses médicos trabalhavam também em consultórios do tipo liberal, o que é um índice bastante inferior à média. Apenas 23,6\% deles trabalham também em algum hospital da cidade ou regiāo. Este dado sugere que a maioria desses profissionais estão em início de carreira, não tendo ainda conseguido um espaço profissional maior.

\section{Representaçōes dos médicos sobre política e administração de serviços de saúde}

Apenas um terço dos médicos que trabalham na rede pública de Campinas negam explicitamente a necessidade de Supervisão e de Avaliação do trabalho médico por outros profissionais. Este fato evidencia que eles estão, majoritariamente, predispostos a aceitar instrumentos de controle sobre o seu trabalho, o que é estranho à tradição do liberalismo médico ou mesmo ao alto grau de autonomia que efetivamente desfrutam. De um modo correspondente, $82,2 \%$ dos entrevistados considera- 
ram necessária a normatização ou padronização de condutas diagnósticas ou terapêuticas.

No entanto, verificou-se uma rejeição bem mais expressiva à idéia de uma possivel fiscalização das atividades profissionais do médico pelos pacientes ou pela comunidade. Neste caso, houve uma divisão igualitária entre os que a rejeitaram e os que a consideraram necessária. A proporção de rejeição confirma tendência relativamente forte no Brasil que diz respeito ao fato da corporação médica julgar-se acima de qualquer crítica, principalmente se proveniente do mundo leigo.

Quanto à delegação de algumas funções atualmente realizadas exclusivamente por médicos a outros profissionais de saúde, $63,4 \%$ dos entrevistados consideram-na necessária. É inportante destacar que este procedimento é corriqueiro nos serviços de assistência primária da rede pública de saúde. Diante disso, o fato de $36,6 \%$ o terem considerado ou dispensável ou descabido é bastante expressivo.

Sobre se o Sistema Unificado e Descentralizado de Saúde (SUDS) de fato consitui uma alternativa adequada para a melhoria dos serviços de saúde, principalmente no que diz respeito a uma melhor utilização dos recursos já existentes, os médicos dividiram-se entre os que concordavam integralmente com esta afirmação $(51,9 \%)$ e os que concordavam apenas parcialmente ou não tinham opiniâo formada $(42,5 \%)$. A proporção dos que não concordavam foi insignificante $(5,6 \%)$. Estes resultados atestam que havia uma opinião favorável à uma política de saúde de cunho reformista, com o objetivo de adequar mais racionalmente o sistema de saúde às demandas sociais. Quanto ao fato do SUDS não estar imprimindo uma melhor qualidade aos serviços de saúde, $85,4 \%$ concordaram integralmente ou parcialmente com esta questão, o que demonstra uma baixa avaliaçāo dos serviços existentes e uma alta expectativa com relação às mudanças qualitativas no serviço público promovidas pela reforma sanitária.

Ainda sobre o SUDS, $66,1 \%$ dos médicos concordaram com a idéia de que ele favorecia o processo de estatização da medicina e o assalariamento total dos médicos, o que revela desinformação sobre os fatos. É evidente que este sistema não visava à estatização e menos ainda à promoção de assalariamento total dos médicos. É notável ainda o indice relativamente alto de profissionais $(18,9 \%)$ que não tinham qualquer opinião sobre um assunto que, evidentemente lhes dizia respeito.

Sobre o papel do Estado na assistência à saúde, os médicos entrevistados mostraram uma nítida divisão, na qual 48,5\% não concordaram que o Estado devesse ser responsável apenas pela saúde pública e pelo atendimento médico da população carente e $48,1 \%$ concordaram integralmente ou parcialmente com esta opinião, revelando uma se36 paração entre o ideal liberal contrário a uma intervenção estatal abrangente na área da saúde e o ideal de intervenção do Estado nesta área.

Médicos e suas opiniōes sobre determinantes do processo saúde/doença e sobre sua prática profissional

Verificou-se que a maioria dos médicos não compartilhava de uma perspectiva "medicalizante", reconhecendo a primazia das condições sócio-econômicas na determinação da saúde e admitindo a dependência da assistência médica a um conjunto amplo de fatores históricos, sociais e administrativos. Assim, quando questionados se a grande variedade de produtos farmacêuticos à disposição dos médicos no Brasil é conseqüência dos avanços científicos e tecnológicos observados no setor, sendo de fundamental importância para garantir a qualidade da assistência prestada à população, apenas $10,1 \%$ concordaram integralmente, ao mesmo tempo que $64,9 \%$ não concordaram com esta assertiva. Fica evidente, pelo padrão de respostas, que há consciência entre os médicos do peso significativo representado por elementos estranhos à prática médica no mercado de medicamentos.

Este tipo de visão crítica confirma-se na crença de que é possivel prestar assistência médica de boa qualidade trabalhando-se com uma lista básica padronizada de medicamentos e equipamentos que contenha apenas uma parte dos ítens existentes no mercado. Apenas $14,4 \%$ dos médicos não concordaram com essa possibilidade, ao mesmo tempo que $83,4 \%$ concordaram integralmente ou parcialmente com ela. O mesmo padrão de resposta apareceu quando se lhes apresentou uma afirmação que superestimava a importância da existência de equipamentos na assistência pública no Brasil. Neste caso, apenas $16,2 \%$ dos médicos concordaram que a assistência à saúde prestada pelos serviços públicos não é de boa qualidade porque estes não possuem equipamentos modernos.

No que diz respeito à relação entre condições de manutenção de saúde de uma populaçāo, $84,0 \%$ das respostas privilegiaram as condições gerais de vida em relação à assistência médica individual. Já no que diz respeito às práticas alternativas e sua repercussão sobre a saúde dos indivíduos, foi encontrada uma postura surpreendentemente liberal. Apenas $7,7 \%$ das respostas admitiram que as medicinas alternativas, por serem baseadas em tradições populares não científicas, não merecem credibilidade. Este padrão foi também observado diante da questão que perguntava se é correta a política que busca incorporar alguns elementos das práticas alternativas às condutas da medicina oficial (alopática). Neste caso, houve um indice de concordância integral de $52,6 \%$ e de rejeição de 9,9\%. A ampla aceitação desta questão surpreende, 
tendo em vista a resistência que as instituiçōes da medicina, em geral, apresentam diante deste tipo de proposta.

A respeito de se o trabalho da equipe de saúde deve necessariamente ser coordenado por um médico, $31,55 \%$ concordaram plenamente, $19,6 \%$ concordaram parcialmente e $48,5 \%$ não concordaram com esta proposição. A Secretaria Municipal de Saúde de Campinas já admitia, na época da pesquisa, a possibilidade de outros profissionais com formação universitária, que não necessariamente médica, assumirem a chefia de Posto de Saúde, embora ainda não tenha havido um caso nesse sentido.

Diante da afirmativa de que a assistência médico-sanitária deve centrar-se no trabalho médico, uma vez que as outras categorias profissionais de saúde desempenham papéis secundários nesta prática, apenas $10,7 \%$ concordaram integralmente, enquanto $66,7 \%$ não concordaram e $18,3 \%$ concordaram parcialmente. Com relação à variante desta questão, ou seja, se a assistência médico-sanitária não deve, necessariamente, centrar-se no trabalho médico, uma vez que a assistência integral à saúde exige o concurso de outros profissionais da saúde, obteve-se uma expressiva maioria de $80,9 \%$ que concordaram integralmente com esta idéia.

Com o propósito de avaliar em que medida a admissão da necessidade de equipe multiprofissional poderia estar relacionada apenas com justificativas de aumentar a produtividade do trabalho médico, sem que isso significasse renunciar à hegemonia desta profissão sobre as demais, foi perguntado se o trabalho em equipe multiprofissional é importante para evitar o envolvimento do médico com tarefas secundárias. Diante desta questão, $48,8 \%$ dos entrevistados concordaram integralmente; $22,1 \%$ não concordaram e $28,5 \%$ concordaram parcialmente.

Quanto à relação dos médicos com os pacientes do ponto de vista de intercâmbio de informações, $31,1 \%$ dos entrevistados concordam plenamente e $49,4 \%$ concordam parcialmente com a opinião de que o fracasso dos tratamentos se explica, principalmente, pelo fato dos pacientes não seguirem de forma adequada a prescrição. Evidentemente, este tipo de assertiva, apoiado pela grande maioria dos médicos, procura responsabilizar o paciente pelo grande número de insucessos terapêuticos, o que os desobriga de realizar qualquer reflexão mais crítica sobre os limites de sua prática e das instituiçōes onde trabalham.

Com respeito ao paciente conhecer o diagnóstico de sua doença, bem como receber explicações claras sobre o tratamento adotado, houve uma grande maioria $(82,1 \%)$ que concordaram plenamente com este direito. Aqui, esta evidência choca-se com uma das reclamações mais freqüentes dos usuários do sistema de saúde brasileiro, ou seja, o laconismo da maioria dos médicos sempre que se referem ao processo de doença e de tratamento de seus pacientes. Quanto ao argumento de que para a clientela com baixo grau de escolaridade é necessário e, às vezes até prejudicial, a explicação do diagnóstico e condutas adotadas, uma maioria $(66,0 \%)$ não concordou com ele. Embora a maioria rejeite este tipo de afirmativa, é significativo o indice dos que concordaram parcialmente $(22,1 \%)$ ou integralmente $(11,1 \%)$ com ela, indicando a presença de uma atitude discriminatória na forma de relacionamento entre médicos e pacientes conforme o nível cultural destes últimos.

\section{Representações sobre o papel do cooordenador e seu relacionamento com o poder central.}

Todos os coordenadores dos 31 postos ou centros de saúde de Campinas foram entrevistados. Uma vez que em 14 dessas unidades não havia um coordenador efetivo na ocasião da pesquisa, foram realizadas 17 entrevistas. Todos esses profissionais têm formação médica, sendo que a maioria apresenta idade inferior a 35 anos e menos de 3 anos exercendo a função.

Quando mencionam a sua relação com a direção da Secretaria Municipal de Saúde, os coordenadores apontam, de forma praticamente consensual, uma considerável distância entre o nível central e o nível local. De um modo geral, estes agentes não se sentem como dirigentes, como participantes efetivos das decisões estratégicas da instituição. De acordo com a grande maioria deles, falta autonomia decisória para o papel de coordenador. Se há, por exemplo, autonomia para controlar o ponto do pessoal auxiliar, não há para o controle de desempenho de médicos e dentistas.

A Prefeitura é acusada de dificultar o exercício da função de coordenador ao admitir atividades em tempo parcial, o que, diante das obrigações com o atendimento clínico, não permite tempo para se gerenciar o serviço. Além disso, lembrouse também que o nivel municipal frequientemente manipula o serviço para fins clientelísticos e eleitoreiros.

Em várias ocasiões, os coordenadores fizeram comparações entre os gerentes municipais e os estaduais municipalizados. Nesse sentido, os primeiros foram vistos como mais "amadores", com menos especialização e o fato de encontrarem-se vinculados ao serviço em tempo parcial os tornaria menos aptos para aprimorarem o seu desempenho e mais vulneráveis à situação de transição por que passa o serviço.

Já os serviços estaduais, pelo maior grau de institucionalização, apresentariam um papel muito mais definido para os gerentes do que os de Prefeitura. Com a municipalização do serviço através do SUDS, no entanto, a tradição acumulada pelo 
serviço estadual teve de se subordinar ao gerenciamento municipal, gerando insatisfações e representações negativas de vários tipos por parte dos seus coordenadores. Como exemplo desta representação negativa, mencionou-se que, no contexto da municipalização, o coordenador não tem mais poderes nem para selecionar o pessoal de nível superior a ser contratado, nem sequer para repreender ou punir um profissional que mostra empenho insuficiente em seu trabalho. Com tudo isso, o cargo é visto como quase decorativo devido ao seu pouco poder de intervenção.

Uma forma praticamente consensual com que se observou o ferfil ideal do coordenador do serviço refere-se a um profissional com graduação universitária (preferivel, mas não necessariamente médico), com formação em saúde pública e em gerenciamento de serviços de saúde. A sua atividade deveria ocorrer em tempo integral, de modo a permitir realizar e executar o planejamento de toda a unidade, definir regras administrativas, respeitando os direitos e deveres dos funcionários, além de coordenar tecnicamente as várias áreas de serviços, os recursos humanos e o processo de trabalho. Ele deveria ainda dividir o seu tempo igualmente em três áreas: a clínica, a coordenação administrativa e a saúde pública. Esta última área é considerada a mais prejudicada devido à falta de definição política, normatização e organização que pudessem caracterizá-la como uma atividade consistente de saúde integrada voltada à coletividade.

De um modo geral, reconheceu-se a inadequação da formação profissional básica dos coordenadores, muito tecnicista e pouco voltada para o social ou coletivo. Criticou-se, nesse sentido, o fato da instituição não ter nenhuma política própria para formar sanitaristas, embora tenha sido reconhecido que ela não coloca obstáculos para aqueles que se propõem a freqüentar cursos nesta área em outras instituições.

\section{Coordenadores como formuladores de políti- cas públicas}

Os 17 coordenadores entrevistados podem ser classificados em três grupos básicos de acordo com a inserção no mercado de trabalho e a postura ideológica que esta inserção acarreta. Assim, temos os que mantêm vínculo exclusivo em tempo integral com a rede, os que mantêm vínculo parcial, mas almejam um contrato com vínculo integral $e$ os que mantêm um vínculo parcial e não almejam um contrato com vínculo integral. Està caracterizaçāo provou ser consistente no que diz respeito às representações $\mathrm{e}$, principalmente, à capacidade de interpretar o momento e a situação institucional da rede pública de serviços de saúde.

Há 6 coordenadores que mantêm vínculo exclusivo em tempo integral com a rede, sendo que 38 apenas um deles não tem especialização em Saúde Pública. Estes profissionais mostraram representações globalizantes e politizadas que preconizam reformulações das políticas de saúde, tendo em vista a implementação de um sistema único, regionalizado, hierarquizado, universal, igualitário e sob controle público. Preconizam ainda implementar, entre as ações desenvolvidas pelo Posto de Saúde, um exercício efetivo da medicina preventiva que inclua a educação sanitária da comunidade, aspecto este considerado totalmente secundário na prática atual.

Neste esquema, o trabalho médico deveria ser realizado por uma equipe multidisciplinar, dentro de uma concepção de saúde mais holística, integrada e social. Este tipo de trabalho deveria ser também de boa qualidade técnica e com resolutividade local articulada com uma retaguarda de hospitais de nivel secundário e terciário. Ainda nesta concepção, a comunidade deveria exercer papel crucial no controle dos serviços existentes e na implementação de outros serviços de saúde.

Diante deste ideal, a condução prática do serviço tende a ser avaliado negativamente em vários aspectos tópicos, onde as relações de referência e contra-referência não funcionam e as rotinas são seguidas segundo parâmetros casuísticos, sem planejamento e ordem. Embora considerem que a implantação do SUDS represente um avanço considerável no sentido de democratizar, alémide racionalizar o serviço, percebem a situação atual como estando longe de ser democrática. Acreditam, nesse sentido, que se houve uma melhora efetiva no atendimento médico que atualmente é considerado muito mais integrado do que antes, ainda falta desenvolver uma medicina que seja voltada para a promoção da saúde e que, para isso, estimule e coordene atividades educativas para a comunidade.

Porque apresenta uma atitude politizada sobre como deveria funcionar a rede pública de serviços de saúde, este grupo de coordenadores tende a nutrir uma visão crítica das diretrizes e orientações do nível central. Como conseqüencia, não é raro haver discordâncias sobre valores e normas a respeito da condução do serviço, do procedimento terapêutico e, principalmente, do papel a ser exercido pelo coordenador. Nesse sentido, ele tende a ser produtor de conflitos, ou porque procura fazer cumprir o papel de controlar o trabalho e a frequiência no nivel local, ou porque usa o conflito como mecanismo de barganha com o nível central com o propósito de acumular poder, de implementar direçōes que consideram adequadas à sua concepção e de como a rede pública de serviços de saúde deveria se desenvolver.

O segundo grupo de coordenadores corresponde a 7 médicos cujas representações não diferem muito da categoria de profissionais descritos anteriormente. No entanto, o que os caracteriza em 
relação aos precedentes é o aspecto mais fragmentado com que eles percebem a realidade mais imediata de seu trabalho, refletindo uma menor capacidade de formular políticas consistentes para o sistema de saúde. E curioso observar, também, nesta categoria, apoio às iniciativas que visam a integrar as chamadas medicinas alternativas como a homeopatia, a acupuntura e o uso caseiro de ervas medicinais. Este apoio se expressa ao lado de uma postura mais pessimista no sucesso do ideal preventivista baseado num sistema unificado de saúde controlado e gerenciado pelo setor público.

Esta falta de confiança é, de certa forma, consistente com o exercício de um papel de coordenador que não deixa de ser fragmentado em vários aspectos. Considerando que a maioria dos profissionais que se encontram nesta categoria não completaram um curso de especialização em saúde pública ou medicina preventiva; que todos eles trabalham mais da metade de sua jornada de trabalho em vários outros empregos privados; que são forçados a investir pelo menos três quartos de seu tempo de trabalho na rede pública em atividades de atendimento clínico, ou seja, que não encontram tempo suficiente para coordenar adequadamente o serviço, não é surpresa constatar uma percepção pessimista e fragmentada da realidade neste âmbito.

Considerando que o mercado de trabalho para os médicos em geral encontrava-se, na ocasião da pesquisa, numa situação de pleno emprego, os que escolhiam o setor público como única forma de inserção neste mercado o faziam dentro de uma postura que é eminentemente ideológica. Nesse sentido, tanto a primeira como esta última categoria de profissionais poderiam ser denominados de "militantes" com capacidade, mais efetiva no primeiro caso e mais potencial no segundo, de formular políticas públicas consistentes relativas à saúde. Assim sendo, tais agentes são também capazes de apoiar ou resistir a determinadas instruções conforme elas se compatibilizem ou contrariem as sua representações sobre como o serviço deve se desenvolver e suas posturas políticas sobre este processo. Estas duas categorias também identificavam no serviço público de saúde o espaço ideal de construção de sua realização profissional.

O terceiro grupo de coordenadores é composto por 4 profissionais que mostraram ser menos politizados e menos atraídos e envolvidos pela idéia de constituir um sistema público de serviços de saúde, do que os dois últimos grupos. De um certo modo, houve neste grupo a tendência em ver o serviço principalmente sob o ponto de vista clínico, sendo que os principais problemas abordados foram relacionados dentro de um âmbito meramente quantitativo como, por exemplo, a necessidade de um número maior de médicos, pessoal qualificado, aparelhos diagnósticos e acesso a exa- mes clínicos e medicamentos. Nesse sentido, os vínculos com o setor público se mantinham apenas como parte de suas relaçōes com o mercado de trabalho.

Ideologicamente, esses médicos não eram necessariamente privativistas, mas viam o setor público como algo que deveria se preocupar prioritariamente como os setores populacionais "marginais", mostrando pouco interesse sobre a concepção e o desenvolvimento de um sistema único, universal e democrático de saúde, embora pudessem apoiá-lo como concepção geral. Nesse sentido, o processo de municipalização dos serviços de saúde foi visto de modo ambíguo, necessário, de um lado, porque imprime maior racionalidade ao sistema de saúde e perigoso, de outro, porque abre o sistema às ações de politicagens da prefeitura.

A atuação deste grupo ocorria no sentido de cumprir as funções que a instituição lhes colocava, procurando não gerar muito conflito com a equipe local, principalmente porque isto significaria um acúmulo de problema e trabalho. Com esta atitude, tendiam a realizar, implícita ou explicitamente, acordos corporativos como, por exemplo, a não exigência do cumprimento do horário de trabalho para os médicos e dentistas, numa compensação à má remuneração que recebiam pelos seus serviços. O controle do trabalho dos demais profissionais da saúde era, no entanto, estrito, embora também eles fossem mal remunerados.

Consideram ainda que a população não entende o que está acontecendo e que, no fundo, a mesma pressiona por mais consulta médica, recusando experiências com trabalho em equipe muldisciplinar, a delegação de algumas funções médicas ao time de auxiliares e a coordenação do Posto por um profissional não médico. Neste contexto, os usuários do serviço foram vistos apenas como clientela sem qualquer poder de participar ou de controlar a política e a administração do sistema. Diante deles, toda a questão resume-se em enquadrá-los conforme os propósitos das tecnologias em saúde que utilizam, sejam elas, por exemplo, demandadores por serviços programáveis ou de "pronto atendimento".

Pela ausência de interesse em formular políticas públicas coerentes ou mesmo de entender, em sua totalidade, o processo de mudanca em curso nessa área, esse grupo pode ser denominado "pragmático", com capacidade limitada, efetiva ou potencial, de desenvolver projetos políticos para a implementação de uma rede pública de serviços de saúde.

\section{Conclusão}

O conjunto desses dados revela um quadro em que, a despeito da educação médica ainda privilegiar um modelo "mecanicista" centrado nas 
ciências naturais e biológicas, é notável a abertura de uma parcela considerável dos médicos pesquisados a fatores sócio-econômicos e culturais na determinação da doença, na manutenção da saúde e no sucesso terapêutico. É também notável a abertura verificada em relação às medicinas alternativas e, consequientemente, à visão de que a ciência não deve nem pode ser encarada como um parâmetro objetivo de verdade independente de avaliação através de critérios sociais. Esta abertura corresponde a uma representação diametralmente oposta daquela que, sabidamente, vigorava entre os médicos de modo predominante até poucas décadas atrás, a qual correspondia a um papel autoritário, autônomo e insubmisso a qualquer avaliação sobre o seu desempenho profissional por parte da sociedade.

Destaca-se, também, nessas representações, a disposição para trabalho em equipe, mesmo que o coordenador do serviço não seja um profissional médico. Admitir a delegação de responsabilidades sobre questões de saúde e doença a outros profissionais da saúde significa uma verdadeira ruptura com o caráter individualista e carismático do médico que tradicionalmente não admite outro relacionamento com uma equipe de trabalho que não fosse baseada na submissão aos seus próprios métodos e critérios. Esta representação, no entanto, não se mostrou conflitiva com a pretendida hegemonia do médico entre os profissionais que formam a equipe de trabalho.

Formular um ponto de vista crítico com respeito à indústria farmacêutica e hospitalar é uma outra questão que, de uma certa forma, coloca o médico num campo de atuação mais próximo da população a que serve e mais independente das forças econômicas e políticas da sociedade mais ampla. Essa questão é particularmente importante se for considerado que um dos sutentáculos do prestígio e do poder usufruido pela profissão médica provém exatamente do seu papel de controle social em geral e da força de trabalho industrial em particular.

É importante reconhecer, no entanto, que estamos tratando de representações e que existe uma certa distância entre estas e as ações práticas realmente desempenhadas e vividas. Isso significa, em outras palavras, que nem sempre o que os individuos dizem correspondem ao que eles fazem na realidade. No entanto, é inegável que essas representaçōes e atitudes influenciam de algum modo a prática.

A UNICAMP surge como um fator importante na difusão desta percepção menos positivista e mais social da medicina entre os médicos da rede básica de serviços de saúde de Campinas. Esta influência ocorre não só pelo número de médicos egressos daquela universidade que a rede básica emprega (cerca de $40 \%$ na ocasião da pesquisa), mas também pelos vários cursos em nível de especialização e pós-graduação, pelos seminários e congressos que, de um modo mais ou menos direto, influenciam inevitavelmente a prática médica desse serviço. Além disso, há que se destacar também o fato dos dois últimos secretários municipais de saúde do municipio terem sido oriundos dessa Universidade.

Uma área de dificuldade no processo de municipalização do serviço público de saúde ocorre por estar sendo realizado sem a participação de seus coordenadores. É um paradoxo o fato de que um processo de descentralização como o que se tenta empreender seja realizado de um modo tão centralizado. Ao não se sentirem participantes des te processo, agentes privilegiados, que poderiam oferecer valiosa contribuição para o seu sucesso, observam com alguma perplexidade ao desperdicio de energia e de recursos na realização de um plano que , para ser bem sucedido, deveria começar por captar o seu interesse e apoio.

\section{Agradecimentos}

Ao Prof. Heleno R. Correa Filho, pela orientação estatística; aos pesquisadores Ermínia Silva, Luiz C.O. Cecílio, Márcia A. Amaral; Maria A. Teixeira, Maria G.C. Oliveira e Paulo R.N. Costa pela colaboração no levantamento de dados.

QUEIROZ, M. de S. et al. [The basic health service network: doctors and their representations regarding the service]. Rev. Saúde públ., S.Paulo, 26: 34 - 40, 1992. This article aims to analyse the representations of doctors of public sector in Campinas, SP, Brazil, taking as reference the process of decentralization which the health reform being undertaken in Brazil is undergoing. It is assumed that the sucess of this reform will depend largely on the attitude that these doctors show towards its various aspects. The folowing subjects were then focused on: the policies and management of the health services, the health-disease process, the doctor-patient relationship and labour process as it affects the health team.

Keywords: Physicians. Anthropology. Local health systems.

\section{Referèncias Bibliográficas}

1. GLUCKMAN, M. Custom and conflict in Africa. Oxford, Basil Blackwell, 1973.

2. TURNER, V.W. O processo ritual. Rio de Janeiro, Vozes, 1974.

Recebido para publicação em 4/7/1991

Reapresentado em 21/10/1991

Aprovado para publicacão em 12/11/1991 